\title{
Blunt Thoracic Aortic Injury in Pediatric Patients: Demographics, Assessment and Treatment
}

\author{
Christine Gresik $^{1}$, Thomas Esposito ${ }^{2 *}$, Dana Hommel ${ }^{2}$, Loretto Glynn ${ }^{3}$, Robert Love ${ }^{4}$ \\ ${ }^{1}$ Northwestern University Medical System, Chicago, USA \\ ${ }^{2}$ Loyola University Medical Center, Maywood, USA \\ ${ }^{3}$ Central Dupage Hospital, Winfield, USA \\ ${ }^{4}$ Medical College of Wisconsin, Milwaukee, USA \\ Email: *tesposi@lumc.edu
}

Received November 1, 2012; revised December 4, 2012; accepted December 13, 2012

\begin{abstract}
Background: There is a paucity of information regarding the management of blunt thoracic aortic injury in the pediatric population compared to adults. This article adds three cases of blunt thoracic aortic injuries in pediatric patients to the literature and analyzes these in conjunction with several of the previous case series which have been published. Methods: Three cases were reviewed along with 38 previously reported cases in an attempt to identify trends in demographics and management. The three new cases presented over a four-year period. All are male. A six-year-old and a 17-year-old were involved in motor vehicle crashes and a 10-year-old was struck by a vehicle while skateboarding. Results: The 6-year-old and the 17-year-old were treated non-interventionally due to severe closed head injuries. One received beta blockade. Both survived. The third, without head injury, underwent interposition graft and also survived. Conclusions: These findings are not greatly dissimilar from the adult experience. In reviewing all 41 pediatric cases, findings reveal a high mortality, predominantly due to head injury as well as the aortic injury. Open repair and interposition grafting continue to be the mainstay of management, with endovascular procedures and non-operative management becoming more prevalent recently. The role of beta-blockade is unclear in children with this injury. Further multicenter prospective studies of this rare pediatric injury may be useful.
\end{abstract}

Keywords: Blunt Thoracic Aortic Injury; Pediatric Thoracic Aortic Injury; Aortic Trauma

\section{Introduction}

Over the past 30 years, multiple case series have been published describing blunt thoracic aortic injury in the pediatric population [1-5]. Evidence points to a relative paucity of this injury in children compared to adults. Similar mortality rates of about $85 \%$, primarily occurring at the scene of injury have been demonstrated [6]. However, there is a lack of clear consensus regarding proper screening, diagnosis, and treatment for those patients who reach the hospital alive after high risk mechanisms for this injury in the pediatric population. Since the vast majority of blunt thoracic aortic injuries occur in adults, generally accepted practices have been established for the injury in these patients, but it is unknown whether such practices can be applied to pediatric patients with similar injuries [6,7].

This report adds three additional cases to the literature. Each provides a unique example of blunt thoracic aortic injury in children which combined with data from previ-

${ }^{*}$ Corresponding author. ous case series, provides an opportunity for analysis and synthesis of information about this rare pediatric injury.

\section{Materials and Methods}

The cases of three consecutive pediatric patients with blunt thoracic aortic injuries occurring between July 2008 and August 2009 and treated at a Level 1 Trauma Center were reviewed. All patients were male, two were involved in high speed motor vehicle collisions (MVC) and one was a pedestrian struck by an automobile. Details of each case follow. Patient characteristics are summarized in Table 1. A literature search was then conducted. This yielded five other case series. These collectively produced 38 patients who were 19 years old or younger that sustainedblunt thoracic aortic injury between 1981 and 2009. Patient data from these other case series were then combined and analyzed collectively with this study's findings.

\subsection{Case 1}

This is 6-year-old male who was a restrained passenger 
Table 1. Patient characteristics—current study.

\begin{tabular}{|c|c|c|c|c|c|c|c|c|c|}
\hline $\begin{array}{l}\text { Case No./ } \\
\text { Sex/Age }\end{array}$ & Mech & Restraint & GCS & Aortic Injury & Screening & Confirmation & Associated Injuries & Survival & $\begin{array}{c}\text { Neuro } \\
\text { Sequellae }\end{array}$ \\
\hline $1 / \mathrm{M} / 6 \mathrm{y}$ & $\begin{array}{l}\text { MVC-prolonged } \\
\text { extrication }\end{array}$ & restrained & $3 \mathrm{~T}$ & $\begin{array}{l}\text { Pseudoanurism } \\
\text { at isthmus }\end{array}$ & $\begin{array}{c}\text { CXR } \\
\text { non-specific } \\
\text { for aortic injury }\end{array}$ & $\mathrm{CT}$ & $\begin{array}{l}\text { Cardiac arrest } \times 10 \text { mins, } \\
\text { CHI, Pulm contusion, B } \\
\text { PTX, C1 C } 2 \mathrm{fx}, \text { rib } \mathrm{fx} \\
\text { clavicle } \mathrm{fx}\end{array}$ & Alive & $\begin{array}{l}\text { Persistent } \\
\text { vegetative } \\
\text { state }\end{array}$ \\
\hline $2 / \mathrm{M} / 10 \mathrm{y}$ & Ped v MVC & $\mathrm{n} / \mathrm{a}$ & 15 & $\begin{array}{l}60 \%-70 \% \\
\text { transection }\end{array}$ & $\begin{array}{l}\text { CXR showed } \\
\text { widened MS }\end{array}$ & $\mathrm{CT}$ & $\begin{array}{c}\text { Traumatic } 3^{\text {rd }} \text { nerve palsy, } \\
\text { right tibia and fibula } \\
\text { fractures }\end{array}$ & Alive & None \\
\hline 3/M/17 y & MVC-ejected & restrained & $11 \mathrm{~T}$ & $\begin{array}{l}\text { Pseudoanurism } \\
\text { at isthmus }\end{array}$ & $\begin{array}{l}\text { Abnormal CXR, } \\
\text { loss of aortic } \\
\text { knob definition, } \\
\text { NO widened MS }\end{array}$ & $\begin{array}{c}\text { CTA, } \\
\text { Aortogram }\end{array}$ & $\begin{array}{l}\text { CHI, pulm contusion, } \\
\text { PTX, pleural effusion, } \\
\text { odontoid burst fx, bilateral } \\
\text { clavicle fx, multiple } \\
\text { thoracic spinal fx, multiple } \\
\text { splenic lacerations, } \\
\text { kidney laceration }\end{array}$ & Alive & None \\
\hline
\end{tabular}

in a vehicle involved in a high speed collision. The patient was reported to be apneic and asystolic. The patient underwent ten minutes of cardiopulmonary resuscitation (CPR), and his rhythm returned to sinus tachycardia. Upon arrival to the trauma bay, primary survey revealed an unconscious, child with oxygen saturations in the low $80 \mathrm{~s}$ and absent left sided breath sounds. After left tube thoracostomy, his oxygen saturation improved to $97 \%$ $100 \%$. He remained in sinus tachycardia with a heart rate of 140 beats/minute and blood pressure of 140/80. He was unresponsive to noxious stimuli and his pupils were fixed and dilated. His Glasgow Coma Scale (GCS) on admission was 3T.

Chest radiograph showed an enlarged heart, and left upper lung opacity, consistent with atelectasis or pulmonary contusion. There was no evidence of mediastinal widening or loss of aortic knob contour. Computed tomography (CT) of the chest showed a post traumatic pseudoaneurysm at the aortic isthmus, mediastinal hematoma and a hematoma surrounding the arch and descending aorta. His other injuries were a closed head injury (subarachnoid hemorrhage in the foramen magnum and basal cisterns), a C1-C2 fracture (anterior displacement and distraction, ligamentous injury, and possible compression of the medulla and upper cervical cord), bilateral pneumothoraces, severe pulmonary contusions, left rib fractures, and a left clavicle fracture. He was severely acidemic. Initially, the patient was hypertensive, but precipitously developed severe hypotension and bradycardia requiring dobutamine. His persistent hypotension precluded use of beta-blockers though their use was considered to prevent pseudoaneurysm propagation. Cardiovascular surgery recommended continued medical management rather than surgical intervention, due to the patient's severe pulmonary contusions and probable anoxic brain injury.

Throughout his hospital stay, there was no clinical evidence of extension of the tear or expansion of the aortic pseudoaneurysm on subsequent CT scans. The patient's neurological function remained extremely poor. Despite a very poor prognosis, the family desired aggressive care for the patient. He was transferred to a long term care facility. Follow-up chest CT at two months showed no change from $\mathrm{CT}$ at discharge.

\subsection{Case 2}

This is 17 -year-old male was initially treated at another hospital after being involved in a high speed motor vehicle crash and ejected. He was transferred due to a concern for aortic injury, in addition to a known head injury and cervical spine fracture. On arrival at the Trauma Center, he was able to follow commands in all four extremities, with a GCS of $11 \mathrm{~T}$. Initial chest radiograph showed loss of definition of the aortic knob, layered left pleural effusion, right pneumothorax and bilateral clavicular fractures, but no widening of the mediastinum. Initial CT of the chest showed a "smoothly marginated contrast collection" for which the differential diagnosis included ductus diverticulum versus traumatic pseudoaneurysm. Additional injuries identified were small subdural and intra-parenchymal hematomas, left rib fractures, odontoid burst fracture, multiple thoracic spinal fractures, splenic lacerations and a left kidney laceration with retroperitoneal hematoma. He underwent immediate exploratory laparatomy with splenectomy.

An aortogram was completed four days later to further characterize his aortic injury. At this time it was identified as a focal aortic pseudoaneurysm at the site of the ligamentum arteriosum without extravasation of contrast. Non-operative treatment was chosen due to the patient's concurrent head injury and odontoid burst fracture. Instead, the patient received titrated beta-blockade to maintain systolic blood pressures below $120 \mathrm{mmHg}$. He was later found to have a loculated left intrathoracic fluid 
collection which was treated with video assisted thoracoscopic surgery (VATS). He had an expedient and uneventful recovery and was discharged on hospital day 17 .

He was followed with serial CT scans, with the possibility of endograft stenting in the future if needed. However, due to progressive decrease in the size of the aneurysm, this was not performed. At ten month follow up, the patient was well except for mild shortness of breath and palpitations with activity. CT showed a very small luminal irregularity, without surrounding hematoma or focal dissection. He will continue to be followed with CT or Magnetic resonance (MR) angiograms at increasing intervals.

\subsection{Case 3}

This is a 10-year-old male who was skateboarding to school when he was struck by a motorvehicle at an unknown speed. He was transferred from an initial hospital due to findings of closed head injury, right tibia and fibula fracture, and possible aortic tear. Upon arrival at our institution, chest x-ray showed a widened mediastinum. His head CT showed no intracranial abnormalities. CT of his chest showed an aortic transection with a contained hematoma. While non-operative and endovascular management strategies were discussed, based on the chest CT findings it was determined that this injury would be best managed by urgent open repair. Endovascular repair was determined not to be possible due to the patient's small size. The patient was cleared for systemic anticoagulation by neurosurgery. His anteriomedial aortic transacttion $(60 \%-70 \%)$ was repaired using an interposition 16 $\mathrm{mm}$ tube dacron graft utilizing circulatory bypass via the femoral vessels. The patient did well after the procedure and returned to the operating room two days later for fixation of his right tibial-fibular fracture. He was discharged to home nine days after his admission. He remained well at a follow up visit two months later. His chest $\mathrm{x}$-ray was within normal limits.

\section{Discussion and Literature Review}

Patients 1 and 2 are similar in that both patients were involved in high speed MVCs and sustained injuries at the most common location for blunt aortic injury, the aortic isthmus [5]. The decision to treat the aortic injuries non-operatively was dictated by the presence of severe closed head injuries in both cases. One patient tolerated medical management with the aid of beta-blockade, while the other was managed without any intervention. Despite the lack of procedural intervention, neither patient suffered any morbidity or mortality due to the aortic pseudoaneurysms. Follow-up with contrast CT at two and ten months respectively for patients 1 and 2 showed no significant interval change from hospital discharge.

The third patient had an aortic injury which was considered potentially lethal and did not have a significant head injury. This prompted immediate open repair, rather than non-operative management.

Collective information regarding patient demographics, treatment options and outcomes from each previous study as well as the studies combined are shown in Tables 2-4.

\subsection{Patient Demographics}

Blunt thoracic aortic injury was more common in males than females ( $70 \%$ males) and is far more common in older pediatric patients than younger children. In the combined series, only 7 patients $(17 \%)$ were less than 11 years old. The mechanism of injury in the majority of cases was MVC (76\%), followed by pedestrians struck by automobile $(10 \%)$ and bicycle incidents $(5 \%)$.

Reports of very young and small patients are rare, yet this subpopulation is of particular interest because these patients differ most significantly from the adult patient in their size and ability to respond to injury. These differences include anatomic discrepancies in vessel circumference which pose a challenge in regards to the appro-

Table 2. Patient characteristics—collective data.

\begin{tabular}{|c|c|c|c|c|c|c|c|c|c|c|}
\hline \multirow{2}{*}{ Study } & \multirow{2}{*}{ Pts } & \multicolumn{3}{|c|}{ Age } & \multicolumn{2}{|c|}{ Sex } & \multicolumn{4}{|c|}{ Mechanism } \\
\hline & & $<11 \mathrm{y}$ & $11-13 y$ & $>13 y$ & Male & Female & MVC & Bike & $\mathrm{P} v \mathrm{~A}$ & Other \\
\hline Totals & 40 & 7 & 12 & 22 & 29 & 12 & 31 & 2 & 4 & 4 \\
\hline Gresik & 3 & 2 & 0 & 1 & 3 & 0 & 2 & 0 & 1 & 0 \\
\hline Hormouth & 11 & 0 & 4 & 7 & 8 & 3 & 7 & 0 & 3 & 1 \\
\hline Karmy-Jones & 11 & 2 & 5 & 4 & 10 & 1 & 10 & 0 & 0 & 1 \\
\hline Takach & 3 & 2 & 0 & 1 & 2 & 1 & 3 & 0 & 0 & 0 \\
\hline Trachiotis & 6 & 1 & 1 & 4 & 1 & 5 & 5 & 1 & 0 & 0 \\
\hline
\end{tabular}


Table 3. Diagnosis and management of aortic injuries.

\begin{tabular}{|c|c|c|c|c|c|c|c|c|c|c|}
\hline \multirow[b]{2}{*}{ Study } & \multirow[b]{2}{*}{ Pts } & \multicolumn{3}{|c|}{ CXR Signs* } & \multicolumn{3}{|c|}{ Confirmation ${ }^{*}$} & \multicolumn{3}{|c|}{ Management } \\
\hline & & $\begin{array}{l}\text { Widened } \\
\text { mediastinum }\end{array}$ & $\begin{array}{l}\text { Aortic knob } \\
\text { changes }\end{array}$ & $\begin{array}{l}\text { Non-specific/Unknown } \\
\text { changes }\end{array}$ & $\mathrm{CT} / \mathrm{CTA}$ & Aortogram & TEE & OR & Endograft & Non-operative \\
\hline Totals & 40 & & & & 20 & 26 & 5 & 31 & 3 & 7 \\
\hline Gresik & 3 & 1 & 1 & 1 & 3 & 1 & 0 & 1 & 0 & 2 \\
\hline Anderson & 7 & $\neq$ & $\neq$ & $\neq$ & 7 & 2 & 1 & 4 & 0 & 3 \\
\hline Hormouth & 11 & 11 & 5 & 1 & 2 & 9 & 0 & 11 & 0 & 0 \\
\hline Karmy-Jones & 11 & 11 & 0 & 0 & 3 & 11 & 1 & 6 & 3 & 2 \\
\hline Takach & 3 & 3 & 0 & 0 & 3 & 0 & 0 & 3 & 0 & 0 \\
\hline Trachiotis & 6 & 0 & 0 & 6 & 2 & 3 & 3 & 6 & 0 & 0 \\
\hline
\end{tabular}

*: Multiple diagnostic signs or modalities used for some patients; $¥$ : CXR results not reported.

Table 4. Patients with non-operative management.

\begin{tabular}{|c|c|c|c|c|c|c|c|c|c|c|c|}
\hline Author & Pt \# & $\begin{array}{l}\text { Age } \\
(y)\end{array}$ & Sex & Mech & GCS & $\begin{array}{l}\text { Head } \\
\text { Injury }\end{array}$ & $\begin{array}{c}\text { Respiratory } \\
\text { Injury }\end{array}$ & Ortho Injury & Abd Injury & Survival & $\begin{array}{c}\text { Neuro } \\
\text { Sequellae }\end{array}$ \\
\hline Gresik & 1 & 6 & M & MVC & $3 \mathrm{~T}$ & $\mathrm{CHI}$ & $\begin{array}{l}\text { Pulm } \\
\text { contusion, } \\
\text { B PTX }\end{array}$ & $\begin{array}{l}\mathrm{C} 1 \mathrm{C} 2 \mathrm{fx}, \mathrm{rib} \mathrm{fx} \\
\text { clavicle fx }\end{array}$ & None & Alive & $\begin{array}{l}\text { Persistent } \\
\text { vegetative } \\
\text { state }\end{array}$ \\
\hline Gresik & 3 & 17 & M & MVC & $11 \mathrm{~T}$ & $\mathrm{CHI}$ & $\begin{array}{l}\text { Pulmo } \\
\text { contusion, } \\
\text { PTX, pleural } \\
\text { effusion }\end{array}$ & $\begin{array}{l}\text { Odontoid burst } \mathrm{fx} \text {, } \\
\text { bilateral clavicle } \mathrm{fx} \text {, } \\
\text { multiple thoracic } \\
\text { spinal } \mathrm{fx}\end{array}$ & $\begin{array}{l}\text { Multiple } \\
\text { splenic } \\
\text { lacerations, } \\
\text { kidney } \\
\text { laceration }\end{array}$ & Alive & None \\
\hline Karmy-Jones & 10 & 12 & & & & $\mathrm{CHI}$ & Pulm contusion & $\begin{array}{l}\text { Pelvic } \mathrm{fx} \\
\text { T spine } \mathrm{fx}\end{array}$ & None & Alive & None \\
\hline Karmy-Jones & 11 & 15 & & & & CHI & & Pelvic fx & None & $\begin{array}{l}\text { Dead } \\
(\mathrm{CHI})\end{array}$ & $\begin{array}{c}\text { Anoxic brain } \\
\text { injury }\end{array}$ \\
\hline Anderson & 1 & 13 & M & Bike & 15 & None & $\begin{array}{c}\text { Pulm } \\
\text { contusion, PTX }\end{array}$ & $\begin{array}{l}\text { Rib fx, femur } \mathrm{fx} \\
\text { acromion } \mathrm{fx}\end{array}$ & $\begin{array}{l}\text { Liver lac, } \\
\text { kidney } \\
\text { contusion }\end{array}$ & Alive & None \\
\hline Anderson & 3 & 13 & M & ATV & 15 & None & None & Radius fx & Splenic lac & Alive & None \\
\hline Anderson & 5 & 15 & M & MVC & 15 & Scalp lac & None & Rib fx, spine $f x$ & None & Alive & None \\
\hline
\end{tabular}

priate sizing of an interposition graft and potential difficulty with cannulation of smaller caliber blood vessels. However the small number of reported cases makes it difficult to make management recommendations, specifically for small children. The male to female ratio in this group was close to $50 \%$, as compared to the $70 \%$ seen in older children and adults. All seven patients survived and only one had a poor neurological outcome, which was ascribed to his head injuries rather than aortic injury.

\subsection{Treatment Options}

Historically, the standard of care for acute aortic transection has been immediate open operative repair, either primarily or with interposition grafting. However, more recent studies in adults have shown that aortic injuries can be managed non-operatively, particularly while other injuries are evaluated and treated and the patient is stabilized [3]. Currently, three options exist for the management of these injuries: open operative treatment, endovascular stenting, and non-operative, medical management.

There were 31 patients in the collective series that had operative repair of their aortic injuries. Three of these were primary repairs, while the other 28 included some form of graft repair. Open operative repair is associated with significant morbidity, especially when compared to the other treatment options. Complications of operative repair include acute renal failure, partial paralysis secondary to spinal cord ischemia and recurrent laryngeal nerve injury along with the morbidity of thoracotomy 
incision. Within this group there was only one death, which was due to head injury, rather than aortic rupture. There were also five patients with long term neurological deficits. One patient had paraplegia on admission but the other four developed the deficits after surgery. Long term durability of those repaired with interposition grafts was largely unavailable. It remains undetermined as to whether or not these grafts remain durable with growth or whether they should be replaced with a larger size as the child ages.

Although the use of cardiopulmonary bypass has become routine and significantly reduced the rate of paralysis associated with the aortic repair itself, concerns with the need for systemic anticoagulation in the face of brain injury and/or polytrauma have been an impetus to shift toward non-operative or endovascular management. Another intermediate option to be considered has been left atrial-femoral bypass which utilizes little or even no heparinization.

Treatment of blunt aortic injuries in adults is transitioning from open repair to endovascular stent grafting [3]. Karmy-Jones applied this concept to three pediatric patients with blunt thoracic aortic injuries. Two of the patients underwent endovascular stent grafting uneventfully and without immediate complications. One patient, whose injury was very close to the origin of the left subclavian artery, had a persistently filling pseudoaneurysm after the repair, which required the placement of a second stent. Endovascular leak decreased but never fully resolved. Unfortunately, two of the three patients (including the patient with persistent endovascular leak) met criteria for brain death within one week of the procedure preventing any comment on long term follow up. In all cases, the brain death was thought to be secondary to injury sustained at the time of trauma and not related to the endovascular intervention. The third patient did well. A repeat CT angiogram done at routine one year follow up showed no migration of the stent or endovascular leak. In this series the authors do not describe difficulty with femoral vessel cannulation though these patients were older than 11 years. In addition, the short follow-up of only one year does not adequately assess long term durability. These data are insufficient to make statements regarding a standard of care, but do introduce the possibility of safely applying this adult treatment strategy to pediatric patients. This raises the question of whether future treatment algorithms might be developed based on body surface area or diameter of vessels as opposed to age alone. However, this does not take into account changes in the characteristics of the aorta with increasing age and the effect on endovascular grafts.

Two common concerns are cited in relation to the use of endovascular stenting in children. The first, as mentioned, is that children's vessels are smaller, which can make it difficult to cannulate the femoral or other vessels used to access the aorta. This also poses a challenge regarding the appropriate size of an interposition graft. Second, children have a smaller "landing zone" necessary to ensure adequate fixation to healthy aortic tissue, which makes placement of the graft more technically challenging and increases risks for complications such as endoleak, migration, aneurysm pressurization and loss of renal function $[3,8]$. No differences in regard to stenosis or pseudoaneurysm at the cannulation site have been reported to date. Another concern which is less often considered, but of increasing attention, is the cumulative effect of repeated irradiation incurred to follow these patients for endoleak and endograft migration. This risk of subsequent malignancy related to irradiation is not insignificant in the pediatric population [9].

Non-operative treatment was selected in seven of the patients in the combined series. Three of these patients were treated in this manner specifically because their head injuries were considered a prohibitive operative risk. Of these three, one patient died of his head injury. The second had severe neurologic deficits due to brain and spinal cord trauma. The third patient, who had been diagnosed with a pseudoaneurysm at the aortic isthmus, survived neurologically intact without further symptoms of his aortic injury. The other four patients who were treated non-operatively did not have complete transections. Three patients had intimal tears and one had an aortic pseudoaneurysm. All four made full recoveries. This limited information suggests that medical management may be a valuable treatment option without the complications associated with procedural intervention, particularly for those patients too unstable for surgery or those with minor aortic injuries.

The use of beta-blockers in the pediatric population has been evaluated in Marfan's Syndrome, congestive heart failure, dilated cardiomyopathy and more recently thoracic aorta disruption [10,11]. None of these studies reported any severe beta-blocker related adverse events. However, they provide insufficient data to formulate a reliable recommendation regarding their use in children with blunt thoracic aortic injury. Specifically, this may not be an acceptable option in those patients with closed head injuries as decreasing systemic arterial pressure would impact the cerebral perfusion pressure.

\subsection{Outcomes-Survival and Neurological Sequellae}

It is well established that $85 \%-90 \%$ of patients with blunt thoracic aortic injuries do not survive long enough to reach the hospital [6]. Considering all patients younger than 19 who survived to be treated at a hospital, only 41 patients over a 25 -year-period exist. In this combined 
case series, only four patients with blunt thoracic aortic injury died after arrival to the hospital. This $90 \%$ survival is significantly greater than the estimated $50 \%$ to $70 \%$ survival in adults with similar injuries [6]. Additionally, all four of these patients ultimately died of head injuries, not aortic injuries, which is also the major cause of mortality reported in adults.

Of the seven patients who survived with permanent neurological sequellae, six were treated operatively and five of these six did not present with neurologic symptoms. The delayed deficits were not attributed to the operative management but rather were ascribed to prolonged hypotension with brain ischemia during initial resuscitation efforts.

Traumatic aortic injury in children is exceedingly rare. This study demonstrates that blunt thoracic aortic injury in children is often associated with severe head and chest injuries likely secondary to the significant force and energy of the injury. It is postulated that the aorta is not as tightly tethered in growing children which more than likely accounts for this lesser incidence in comparison to adults. In addition, the higher survival rate in children is likely due to children having a better stress response as well fewer comorbidities.

No clear consensus can be drawn based on the limited number of cases available for analysis with regard to management, particularly the emerging role of endovascular techniques and their applicability in pediatric patients or the use of beta-blockers in children. Further multicenter prospective or retrospective studies may be warranted to establish guidelines for therapy in clearly defined populations.

\section{REFERENCES}

[1] S. A. Anderson, M. Day, M. K. Chen, et al., "Traumatic Aortic Injuries in the Pediatric Population," Journal of Pediatric Surgery, Vol. 43, No. 6, 2008, pp. 1077-1081. doi:10.1016/j.jpedsurg.2008.02.030

[2] D. Hormuth, D. Cefali, T. Rouse, J. Cutshaw, W. Turner Jr. and G. Rodman Jr., "Traumatic Disruption of the Thoracic Aorta in Children," Archives of Surgery, Vol. 134, No. 7, 1999, pp. 759-763. doi:10.1001/archsurg.134.7.759

[3] R. Karmy-Jones, E. Hoffer, M. Meissner and R. D. Bloch, "Management of Traumatic Rupture of the Thoracic Aorta in Pediatric Patients," The Annals of Thoracic Surgery, Vol. 75, No. 5, 2003, pp. 1513-1517. doi:10.1016/S0003-4975(02)04838-5

[4] T. J. Takach, M. P. Anstadt and H. V. Moore, "Pediatric Aortic Disruption," Texas Heart Institute Journal, Vol. 32, No. 1, 2005, pp. 16-20.

[5] G. D. Trachiotis, J. E. Sell, G. D. Pearson, G. R. Martin and F. M. Midgley, "Traumatic Thoracic Aortic Rupture in the Pediatric Patient," The Annals of Thoracic Surgery, Vol. 62, No. 3, 1996, pp. 724-731. doi:10.1016/S0003-4975(96)00355-4

[6] G. McGwin Jr., D. A. Reiff, S. G. Moran and L. W. Rue, "Incidence and Characteristics of Motor Vehicle Collision-Related Blunt Thoracic Aortic Injury According to Age," Journal of Trauma, Vol. 52, No. 5, 2002, pp. 859865. doi:10.1097/00005373-200205000-00007

[7] K. Nagy, T. Fabian, G. Rodman, G. Fulda, A. Rodriguez and S. Mirvis, "Guidelines for the Diagnosis and Management of Blunt Aortic Injury: An EAST Practice Management Guidelines Work Group," Journal of Trauma, Vol. 48, No. 6, 2000, pp. 1128-1143. doi:10.1097/00005373-200006000-00021

[8] Z. L. Milas, R. Milner, E. Chaikoff, M. Wulkan and R. Ricketts, "Endograft Stenting in the Adolescent Population for Traumatic Aortic Injuries," Journal of Pediatric Surgery, Vol. 41, No. 5, 2006, pp. e27-e30. doi:10.1016/j.jpedsurg.2005.12.055

[9] D. J. Brenner and E. J. Hall, "Computed TomographyAn Increasing Source of Radiation Exposure," The New England Journal of Medicine, Vol. 357, No. 22, 2007, pp. 2277-2284. doi:10.1056/NEJMra072149

[10] A.-K. Frobel, M. Hulpke-Wette, K. G. Schmidt and S. Läer, "Beta-Blockers for Congestive Heart Failure in Children," Cochrane Database of Systematic Reviews, No. 1, 2009, Article ID: CD007037.

[11] R. Shaddy, L. Tani, S. Gidding, et al. "Beta-Blocker Treatment of Dilated Cardiomyopathy in Children: A MultiInstitutional Experience," The Journal of Heart and Lung Transplantation, Vol. 18, No. 3, 1999, pp. 269-274. doi:10.1016/S1053-2498(98)00030-8 